\title{
Seasonality in Flares and Months of Births of Patients with Ulcerative Colitis in a Chinese Population
}

\author{
Aiping Bai · Yuan Guo $\cdot$ Yuhuan Shen · Yong Xie · \\ Xuan Zhu $\cdot$ Nonghua Lu
}

Received: 4 June 2008/ Accepted: 16 July 2008/Published online: 3 December 2008

(c) The Author(s) 2008. This article is published with open access at Springerlink.com

\begin{abstract}
Background and Aims Reports on seasonality in flares or months of births of inflammatory bowel disease patients have been inconsistent, but little data are available in a Chinese population. The aim of this study was to determine whether symptom flares and births of ulcerative colitis (UC) patients follow a seasonal pattern. Methods Patients with a diagnosis of UC established between January 1990 and December 2007 were investigated according to the occurrence of flares of symptoms and months of births. The expected flares or births were calculated on a monthly basis over the study period, taking into consideration the difference in the number of days in the month in each year. Results A total of 409 UC patients were included in the study, and 1030 flares of symptoms were determined. The peak number of flares occurred during the spring and summer, especially in June, while the nadir occurred in the winter, especially in January $\left(\chi_{(11}^{2} d f\right)=32.74304$, $P<0.005)$. The symptom flares also occurred more frequently in the spring-summer period than in the autumnwinter period $\left(\chi_{(3 d f)}^{2}=22.1269, P<0.001\right)$. There was no statistical difference in birth distribution on a monthly
\end{abstract}

A. Bai $(\bowtie) \cdot$ Y. Xie $\cdot$ X. Zhu $\cdot$ N. Lu

Department of Gastroenterology, The First Affiliated Hospital of

Nanchang University, Nanchang 330006, China

e-mail: baiap@163.com

N. Lu

e-mail: lunonghua@163.com

Y. Guo

Department of Pharmacy, The First Affiliated Hospital of

Nanchang University, Nanchang 330006, China

Y. Shen

Department of Gastroenterology, The People's Hospital of Yicheng, Yicheng 441400, China or seasonal (spring, summer, autumn, winter) basis. However, the births of UC patients occurred more frequently in the autumn-winter period than in the spring-summer period when the data were merged into these two seasonal components $\left(\chi_{(1 d f)}^{2}=5.255607, P<0.025\right)$. Conclusions The data indicate that the symptom flares of UC occurred more frequently in the spring and summer, while the births of UC patients occurred more often in the autumn and winter. Environmental recurring factors may be associated with the symptom flares of UC, and these factors during pregnancy or postpartum may be associated with susceptibility to UC later in life.

Keywords Environmental factor - Seasonality · Ulcerative colitis

\section{Introduction}

The relationship between environmental factors and outbreaks of various diseases has been of interest to medical practitioners for a long time. Environmental factors are believed to trigger the onset of some diseases in genetically susceptible individuals and to play a significant role in the inflammatory response of these diseases [1-3]. Environmental factors demonstrate seasonal fluctuations and facilitate the pathogenesis of such diseases as peptic ulceration [1], asthma [2], and chronic heart failure [3].

Ulcerative colitis (UC) and Crohn's disease (CD) are collectively referred to as inflammatory bowel disease (IBD) and are both chronic relapsing diseases characterized by alternating periods of remission and active disease. It is currently believed that altered immunological function, resulting from an abnormal interplay between genetic susceptibility and environmental factors, significantly 
contributes to the mucosal inflammation of the intestinal tract [4]. To date, the environmental factors that contribute to the course of IBD have not been well defined, and while the results of some studies suggest that there may be seasonal variation in the natural history of IBD [5-8] as well as seasonality in month of birth of the patients [9, 10], those of other studies do not reveal any such relationship [11-13]. All of these results, however, were based on data obtained from studies carried out in Western (="developed") countries.

To date, little data on the seasonality of flares in terms of patterns of IBD symptoms and month of births of IBD patients are available in Asian populations, especially the Chinese population. The incidence of IBD has been increasing in China in recent years. However, Chinese patients show somewhat different clinical patterns of IBD from those of their Western counterparts, such as a lower manifestation of fistulae and perianal diseases and a lower incidence of family history [14], which may be attributed to racial genetic predisposition, different cultural background, and dietary habits [15]. Consequently, there may be the seasonality of flares or births of IBD patients in China may show different patterns from those of IBD patients in Western countries. The purpose of this study was to determine whether symptom flares or births of Chinese patients follow a seasonal pattern.

\section{Patients and Methods}

This study was performed in two gastroenterology (GI) units: the Department of Gastroenterology, the First Affiliated Hospital, Nanchang University, and the Department of Gastroenterology, the People's Hospital of Yicheng. Almost all of the UC patients came from the Westeast Lake District and Nanchang County of Nanchang City, and Yicheng County of Yicheng City. The diagnosis of UC had been established by clinical, endoscopic, histological, and/ or radiological criteria [16]. Endoscopy was performed in most of the patients and revealed typical signs of UC. Flares were diagnosed only on the basis of typical symptoms without endoscopy in a small proportion of the patients. Infections or parasites were excluded by stool culture and microscopic examination. Patients with a diagnosis of UC colitis established between January 1990 and December 2007 were included in this study and investigated for seasonality of flares of symptoms and the month of births.

Data on the flares of symptom were retrospectively assessed by the appearance of typical symptoms, such as diarrhoea, abdominal pain, weight loss, perianal fistula/ abscess, rectal bleeding, extra-intestinal manifestations, or of aggravated conditions of these symptoms so that additional medical treatment-in additional to prior therapy-was required. Only those patients who were able to precisely indicate the exact month when symptoms appeared or were aggravated were included in the statistical analysis. The expected flares or births during each year were calculated according to the differences in the number of days in the month of 1 year. Statistical analysis was performed using the chi-square test, and statistical significance was set at a $P$ value of 0.05 .

\section{Results}

A total of 427 UC patients were investigated. The actual months when disease flares or births occurred were established in 409 of the 427 patients $(95.7845 \%)$. Eighteen patients were excluded because the month of disease flares could not be established.

A total of 1030 flares of symptoms were determined from the data collected from those 409 patients, and the observed and expected frequency of disease flares per month is shown in Table 1, taking into account the difference in the number of days in each month between January 1990 and December 2007. Flare peaks occurred in the spring and summer, especially in May, June, and August, compared with the nadir in the winter $\left(\chi_{(11 d f)}^{2}=\right.$ 32.74304, $P<0.005$ ).

Table 2 shows the observed and expected frequency of disease flares on a seasonal basis: spring (March, April, May), summer (June, July, August), autumn (September, October, November), and winter (December, January, February). The ratio of observed to expected number of

Table 1 Observed and expected monthly frequency of disease flares in 409 patients with ulcerative colitis (UC) between January 1990 and December 2007

\begin{tabular}{lcl}
\hline Month of the year & Observed & Expected \\
\hline January & 59 & 87.47945 \\
February & 61 & 79.0137 \\
March & 92 & 87.47945 \\
April & 92 & 84.65753 \\
May & 107 & 87.47945 \\
June & 108 & 84.65753 \\
July & 82 & 87.47945 \\
August & 106 & 87.47945 \\
September & 91 & 84.65753 \\
October & 79 & 87.47945 \\
November & 76 & 84.65753 \\
December & 77 & 87.47945 \\
$\chi_{(11 d f)}^{2}$ & 32.74304 & \\
$P$ value & $<0.005$ & \\
\hline
\end{tabular}


Table 2 Seasonal distribution of disease flares according to season

\begin{tabular}{lll}
\hline Season & Observed & Expected \\
\hline Spring & 291 & 259.6164 \\
Summer & 296 & 259.6164 \\
Autumn & 246 & 256.7945 \\
Winter & 197 & 253.9726 \\
$\chi^{2}(3 d f)$ & 22.1269 & \\
$P$ value & $<0.001$ & \\
\hline
\end{tabular}

flares is 291:259.6, 296:259.6, 246:256.8, and 197:254.0 for the spring, summer, autumn and winter, respectively $\left(\chi_{(3 d f)}^{2}=32.74304, P<0.001\right)$.

Table 3 shows the observed and expected birth cases for the 409 UC patients according to month, taking into consideration the difference in the number of days in each month, between January 1990 and December 2007. These data are combined in Table 4 to show the seasonal distribution of birth cases, and the data on birth distribution is further condensed into a spring-summer and autumnwinter pattern in Table 5. We found no statistical

Table 3 Observed and expected number of birth cases among 409 UC patients according to months of the year patients

\begin{tabular}{lll}
\hline Month of the year & Observed & Expected \\
\hline January & 37 & 34.73699 \\
February & 29 & 31.37534 \\
March & 31 & 34.73699 \\
April & 28 & 33.61644 \\
May & 25 & 34.73699 \\
June & 26 & 33.61644 \\
July & 42 & 34.73699 \\
August & 31 & 34.73699 \\
September & 37 & 33.61644 \\
October & 50 & 34.73699 \\
November & 31 & 33.61644 \\
December & 42 & 34.73699 \\
$\chi_{(11 d f)}^{2}$ & 16.81243 & \\
$P$ value & $>0.1$ & \\
\hline
\end{tabular}

Table 4 Seasonal distribution of birth cases among 409 UC patients

\begin{tabular}{lcc}
\hline Season & Observed & Expected \\
\hline Spring & 84 & 103.0904 \\
Summer & 99 & 103.0904 \\
Autumn & 118 & 101.9699 \\
Winter & 108 & 100.8493 \\
$\chi_{(3 d f)}^{2}$ & 6.724499 & \\
$P$ value & $>0.1$ & \\
\hline
\end{tabular}

difference in birth distribution in the different months $(P>0.1)$ or four seasons $(P>0.1)$; however, more UC patients were born in the autumn-winter period than in the spring-summer period, with the ratio of observed to expected number of births being 183:206.1808 for the spring-summer period and 226:202.8192 for the autumnwinter period $\left(\chi_{(1 d f)}^{2}=5.255607, P<0.025\right)$.

\section{Discussion}

The First Affiliated Hospital of Nanchang University is the only main regional hospital for residents of the Westeast Lake District and Nanchang County of Nanchang City, central-eastern China, and the People's Hospital of Yicheng has the same function for the residents of Yicheng County, central China. Consequently, almost all UC patients in these two areas are referred to these two hospitals for medication, and the number of patients reported here reflects the incidence of UC in these areas between January 1990 and December 2007.

It is well known that environmental factors contribute to inducement of IBD, but the relationship between seasonality and flares of symptoms or births of IBD patients requires further study as results to date have been inconsistent in terms of seasonal variations in the flares of symptoms or birth cases of IBD patients. The results of some studies suggest a degree of seasonality, with increased rates of UC flares being found in the spring and summer in an Italian population [5] or in spring and autumn in Swedish populations [7], while another study found monthly seasonality in symptomatic onset of UC in December and January in a Norwegian population [8]. However, other studies have not found any seasonal pattern of onset or relapse among patients with UC among British [11] and American populations [12]. Conflicting data have also been reported for the seasonal variation of birth cases in IBD patients. One study demonstrated that birth during the winter period in Israel was associated with increased risk to develop $\mathrm{CD}$, whereas birth during the spring was associated with a reduced risk [9], but another study did not find any seasonality in month of birth of IBD in British population of under 20-year-olds [13]. These different

Table 5 Seasonal distribution of birth cases among 409 UC patients based on a spring-summer and autumn-winter pattern

\begin{tabular}{lll}
\hline Combined two-seasons & Observed & Expected \\
\hline Spring-summer & 183 & 206.1808 \\
Autumn-winter & 226 & 202.8192 \\
$\left.\chi_{(1}^{2} d f\right)$ & 5.255607 & \\
$P$ value & $<0.025$ & \\
\hline
\end{tabular}


results among study populations of different races in different geographic areas may reflect the distinct genetic backgrounds of the study populations.

To date, little information on seasonal patterns in flares of IBD or births of IBD patients has been collected among Asian populations, especially the Chinese population. In this study, we determined the seasonal patterns in disease flares and births of patients with UC among a Chinese population. We found a higher frequency of symptom flares in the spring and summer, especially in May, June, and August, with a much lower frequency during the winter. In contrast, the distribution of births of UC patients showed no statistical difference when analyzed on a monthly basis, but most UC birth cases did occur during the autumn-winter period than in the spring-summer period. These data are not consistent with those obtained from Western populations, and the underlying factors for the difference should be intensively studied.

The role of environmental factors in triggering IBD has been the focus of attention for a long time, particularly with respect to bacterial infections. Bacteria and bacterial antigens can modulate the gut immune response and contribute to intestinal inflammation $[17,18]$. The tolerance which exists under a normal healthy state towards resident intestinal flora is broken in active IBD [19], which implies the triggering role of bacterial infection in the flare of IBD. As many human infectious pathogens appear in a regular seasonal pattern [20, 21], seasonal exposure to infectious agents may induce bursts of immune diseases, such as IBD $[22,23]$, and there may be an association between the month of birth and risk of developing IBD later in life [24]. In the Asian area, bacterial infections show a seasonal pattern of occurrence that peaks in the spring and summer $[25,26]$, but viral infections generally occur in the autumn and spring [27], which is slightly different from the seasonality found in Western populations according to a number of epidemiological studies [28, 29]. The infection pattern in the Asian area is consistent with the data of our study, and this consistency may provide a clue for determining the link between bacterial infection and flares of UC, and viral exposure in early life, such as during pregnancy or postpartum, with an increased chance of developing UC later in life. The related studies and potential mechanisms need to be further investigated.

Inflammatory bowel disease is triggered by an inappropriate immune activation in genetically predisposed individuals [18]. Exposure to seasonally variable external factors during the maturation of the immune system is suspected to be an inducing factor for IBD, with the immune response varying in different seasons. For example, the immune function decreases during the winter, when there is a lower production of proinflammatory cytokines and an increased TH1/TH2 ratio [30, 31], which differs from those found during the summer and spring [32, 33]. The possible factors modulating the immune response in different seasons and at different temperatures has been studied by some groups. The warmer temperature can facilitate the locomotion of human neutrophilic leukocytes and lymphoblasts $[34,35]$ and thereby induce the release of inflammatory mediators, such as interleukin (IL)-6 [36, 37]. These fluctuations in immune function in the different seasons may explain the seasonal variations in symptom flares of UC.

The production of adrenal corticosteroids, such as cortisol, have an inhibitory effect on immune function [38]. A recent study which assayed the level of cortisol production in normal individuals found seasonal rhythms in cortisol concentration [39], with peak production occurring in the spring and summer and the lowest production in the autumn and winter. Seasonal fluctuations in cortisol concentration may play a negative role in immune diseases and affect flares of UC.

In conclusion, the results of our analysis of UC patients in a Chinese population are not consistent with those obtained on Western populations and indicate that flares of symptoms occurred mainly in the spring and summer, especially in May, June, and August, and that the birth of UC patients occurred more frequently in the autumnwinter period than in the spring-summer period. The environmental recurring factors may be associated with the symptom flares of UC, and comparable factors during pregnancy or postpartum may be associated with a susceptibility to UC later in life.

Open Access This article is distributed under the terms of the Creative Commons Attribution Noncommercial License which permits any noncommercial use, distribution, and reproduction in any medium, provided the original author(s) and source are credited.

\section{References}

1. Tivon K, Cohen P. Seasonality in duodenal ulcer disease: possible relationship with circannually cycling neurons enclosed in the biological clock. Am J Gastroenterol. 1995;90:1189-1190.

2. Sears MR, Johnston NW. Understanding the September asthma epidemic. J Allergy Clin Immunol. 2007;120:526-529. doi:10. 1016/j.jaci.2007.05.047.

3. Boulay F, Berthier F, Sisteron O, Gendreike Y, Gibelin P. Seasonal variation in chronic heart failure hospitalizations and mortality in France. Circulation. 1999;100:280-286.

4. Xavier RJ, Podolsky DK. Unravelling the pathogenesis of inflammatory bowel disease. Nature. 2007;448:427-434. doi:10. 1038/nature06005.

5. Aratari A, Papi C, Galletti B, et al. Seasonal variations in onset of symptoms in Crohn's disease. Dig Liver Dis. 2006;38:319-323. doi:10.1016/j.dld.2005.10.002.

6. Zeng L, Anderson FH. Seasonal change in the exacerbations of Crohn's disease. Scand J Gastroenterol. 1996;31:79-82. doi: 10.3109/00365529609031631. 
7. Tysk C, Järnerot G. Seasonal variation in exacerbations of ulcerative colitis. Scand J Gastroenterol. 1993;28:95-96. doi: 10.3109/00365529309096052.

8. Moum B, Aadland E, Ekbom A, Vatn MH. Seasonal variations in the onset of ulcerative colitis. Gut. 1996;38:376-378. doi: 10.1136/gut.38.3.376.

9. Chowers Y, Odes S, Bujanover Y, Eliakim R, Bar Meir S, Avidan B. The month of birth is linked to the risk of Crohn's disease in the Israeli population. Am J Gastroenterol. 2004;99:1974-1976. doi:10.1111/j.1572-0241.2004.40058.x.

10. Van Ranst M, Joossens M, Joossens S, et al. Crohn's disease and month of birth. Inflamm Bowel Dis. 2005;11:597-599. doi: 10.1097/01.MIB.0000163697.34592.d4.

11. Lewis JD, Aberra FN, Lichtenstein GR, Bilker WB, Brensinger C, Strom BL. Seasonal variation in flares of inflammatory bowel disease. Gastroenterology. 2004;126:665-673. doi:10.1053/j. gastro.2003.12.003.

12. Auslander JN, Lieberman DA, Sonnenberg A. Lack of seasonal variation in the endoscopic diagnoses of Crohn's disease and ulcerative colitis. Am J Gastroenterol. 2005;100:2233-2238. doi: 10.1111/j.1572-0241.2005.50127.x.

13. Card TR, Sawczenko A, Sandhu BK, Logan RF. No seasonality in month of birth of inflammatory bowel disease cases: a prospective population based study of British under 20-year-olds. Gut. 2002;51:814-815. doi:10.1136/gut.51.6.814.

14. Wang YF, Zhang H, Ouyang Q. Clinical manifestations of inflammatory bowel disease: east and west differences. J Dig Dis. 2007;8:121-127. doi:10.1111/j.1443-9573.2007.00296.x.

15. Wang Y, Ouyang Q. APDW 2004 Chinese IBD working group. Ulcerative colitis in China: retrospective analysis of 3,100 hospitalized patients. J Gastroenterol Hepatol. 2007;22:1450-1455. doi:10.1111/j.1440-1746.2007.04873.x.

16. Ouyang Q, Tandon R, Goh KL, et al. Management consensus of inflammatory bowel disease for the Asia-Pacific region. $J$ Gastroenterol Hepatol. 2006;21:1772-1782. doi:10.1111/j.14401746.2006.04674.x.

17. Bai AP, Ouyang Q. Probiotics and inflammatory bowel diseases. Postgrad Med J. 2006;82:376-382. doi:10.1136/pgmj.2005. 040899.

18. Strober W, Fuss I, Mannon P. The fundamental basis of inflammatory bowel disease. J Clin Invest. 2007;117:514-521. doi: 10.1172/JCI30587.

19. Duchmann R, Kaiser I, Hermann E, Mayet W, Ewe K, Meyer zum Büschenfelde KH. Tolerance exists towards resident intestinal flora but is broken in active inflammatory bowel disease (IBD). Clin Exp Immunol. 1995;102:448-455.

20. Feeney MA, Murphy F, Clegg AJ, et al. A case-control study of childhood. Environmental risk factors for the development of inflammatory bowel disease. Eur J Gastroenterol Hepatol. 2002;14:529-534. doi:10.1097/00042737-200205000-00010.

21. Dowell SF. Seasonal variation in host susceptibility and cycles of certain infectious diseases. Emerg Infect Dis. 2001;7:369-374.

22. Stallmach A, Carstens O. Role of infections in the manifestation or reactivation of inflammatory bowel diseases. Inflamm Bowel Dis. 2002;8:213-218. doi:10.1097/00054725-200205000-00009.

23. Farrell RJ, LaMont JT. Microbial factors in inflammatory bowel disease. Gastroenterol Clin North Am. 2002;31:41-62. doi: 10.1016/S0889-8553(01)00004-8.

24. Haslam N, Mayberry JF, Hawthorne AB, et al. Measles, month of birth, and Crohn's disease. Gut. 2000;47:801-803. doi:10.1136/ gut.47.6.801.
25. Ramani S, Banerjee I, Gladstone BP, et al. Geographic information systems and genotyping in identification of rotavirus G12 infections in residents of an urban slum with subsequent detection in hospitalized children: emergence of G12 genotype in South India. J Clin Microbiol. 2007;45:432-437. doi:10.1128/JCM. 01710-06.

26. Cho SH, Kim JH, Kim JC, Shin HH, Kang YH, Lee BK. Surveillance of bacterial pathogens associated with acute diarrheal disease in the Republic of Korea during one year, 2003. J Microbiol. 2006;44:327-335.

27. Fang ZY, Xie HP, Lv HX, et al. Investigation of human calicivirus $(\mathrm{HuCV})$ diarrhea among infantile and young children in China, 1999-2005. Bing Du Xие Bao. 2007;23:9-15.

28. Nguyen TV, Le Van P, Le Huy C, Weintraub A. Diarrhea caused by rotavirus in children less than 5 years of age in Hanoi, Vietnam. J Clin Microbiol. 2004;42:5745-5750. doi:10.1128/JCM. 42.12.5745-5750.2004.

29. Hearnden M, Skelly C, Eyles R, Weinstein P. The regionality of campylobacteriosis seasonality in New Zealand. Int J Environ Health Res. 2003;13:337-348. doi:10.1080/096031203100016 16128.

30. Boctor F, Charmy R, Cooper E. Seasonal differences in the rythmicity of human male and female lymphocyte blastogenic responses. Immunol Invest. 1989;18:775-784. doi:10.3109/0882 0138909030598.

31. Shirai T, Magara KK, Motohashi S, et al. TH1-biased immunity induced by exposure to Antarctic winter. J Allergy Clin Immunol. 2003;111:1353-1360. doi:10.1067/mai.2003.1504.

32. Termorshuizen F, Garssen J, Norval M, et al. A review of study on effects of ultraviolet irradiation on the resistance to infections: evidence from rodent infection models and verification by experimental and observational human studies. Int Immunopharmacol. 2002;2:263-275. doi:10.1016/S1567-5769(01)00178-3.

33. Termorshuizen F, Geskus RB, Roos MT, Coutinho RA, Van Loveren H. Seasonal influences on immunological parameters in HIV-infected homosexual men searching for immunomodulating effects of sunlight. Int J Hyg Environ Health. 2002;205:379-384. doi:10.1078/1438-4639-00172.

34. McCutcheon M. Studies on the locomotion of leukocytes. The effect of temperature on the rate of locomotion of human neutrophilic leukocytes in vitro. Am J Physiol. 1923;66:185-190.

35. Mandeville RP, Wilkinson PC. Locomotion of human lymphoblasts towards glucose and other sugars. Effects of $\mathrm{pH}$, temperature, and oxygen. Clin Exp Immunol. 1982;36:733-742.

36. Linder M, Larson M, Prellner T, Brattsand R, Laitinen LA. Seasonal variation in the function of blood monocytes obtained from healthy non smokers, asymptomatic smokers, and smokers with chronic bronchitis. Chronobiol Int. 1994;11:266-272. doi: 10.3109/07420529409067794.

37. Maes M, Stevens W, Scharpe S, et al. Seasonal variations in peripheral blood leukocyte subsets and in serum IL-6, and soluble IL-2 and IL-6 receptor concentrations in normal volunteers. Experientia. 1994;50:821-829. doi:10.1007/BF01956463.

38. Bauer ME. Stress, glucocorticoids and ageing of the immune system. Stress. 2005;8:69-83. doi:10.1080/10253890500100240.

39. Matchock RL, Dorn LD, Susman EJ. Diurnal and seasonal cortisol, testosterone, and DHEA rhythms in boys and girls during puberty. Chronobiol Int. 2007;24:969-990. doi:10.1080/07420 520701649471. 